Document downloaded from:

http://hdl.handle.net/10251/141940

This paper must be cited as:

Vague Cardona, JJ.; Melgarejo-Lermas, JC.; Guglielmi, M.; Boria Esbert, VE.; Anza Hormigo, S.; Vicente Quiles, CP.; Moreno Cambroreno, MDR.... (08-2). Multipactor Effect Characterization of Dielectric Materials for Space Applications. IEEE Transactions on Microwave Theory and Techniques. 66(8):3644-3655.

https://doi.org/10.1109/TMTT.2018.2845869

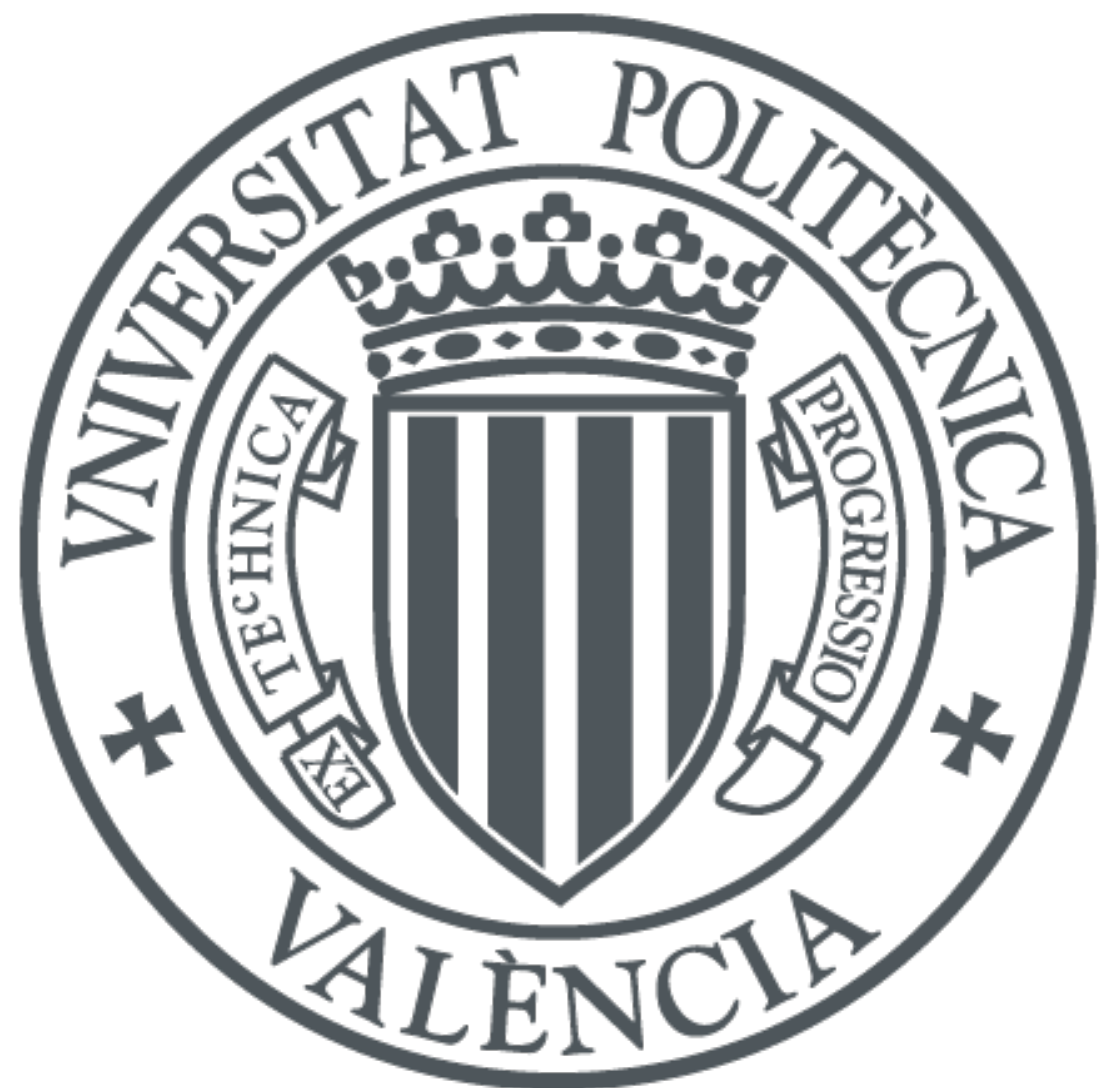

The final publication is available at

https://doi.org/10.1109/TMTT.2018.2845869

Copyright Institute of Electrical and Electronics Engineers

Additional Information 


\title{
Multipactor Effect Characterization of Dielectric Materials for Space Applications
}

\author{
J. Vague, J.C. Melgarejo, M. Guglielmi, Fellow, IEEE, V.E. Boria, Fellow, IEEE, S. Anza, \\ C. Vicente, R. Moreno, M. Taroncher, B. Gimeno, Member, IEEE, and D. Raboso
}

\begin{abstract}
The objective of this work is to advance the stateof-the-art in the characterization of the multipactor effect in dielectric materials. The materials studied are the most commonly used dielectrics in space applications, namely, Alumina, Rexolite, Rogers RT5870, Rohacell, Teflon and Ultem 1000. In this context, a new family of coaxial waveguide components, covering the $\mathrm{L}$ - and S-bands, with a wideband, lowpass response has been designed, and six different prototypes have been specifically optimized and manufactured. The six prototypes have then been used to simulate and measure the multipactor breakdown susceptibility charts for the six dielectric materials investigated. Finally, the simulation results are compared with the results of the measurement campaign indicating good agreement.
\end{abstract}

Index Terms - Alumina, dielectrics, low-pass coaxial filter, multipactor, rexolite, rogers RT5870, rohacell, space applications, teflon, ultem 1000 and wide-bandwidth.

\section{INTRODUCTION}

$\mathrm{D}_{\mathrm{r}}^{\mathrm{s}}$ IELECTRIC MATERIALS are widely used in many passive microwave components for satellite payloads. Radio Frequency (RF) Printed Circuits Boards (PCBs), for instance, implemented either in single- or in multi-layer technology, usually employ high quality substrates such as

Manuscript received January 12, 2018; revised Month DD, YYYY; accepted Month DD, YYYY.

This work was supported by European Space Agency (ESA) through research project "Novel Investigation in Multipactor Effect in Ferrite and other Dielectrics used in High Power RF Space Hardware" (ref. AO 17551/13/NL/GLC), and by MINECO (Spanish Government) under R\&D project TEC2016-75934-C4-1-R.

This paper is an expanded version from the IEEE MTT-S International Microwave Workshop Series on Advanced Materials and Processes IMWSAMP 2017, September 20-22, 2017, Pavia, Italy. (Corresponding author: Joaquín Vague).

J. Vague, J.C. Melgarejo, M. Guglielmi, V.E. Boria and M. Taroncher are with Universitat Politecnica de Valencia, E-46022, Valencia, Spain. (Email:jvague@dcom.upv.es,vboria@dcom.upv.es)

R. Moreno is with Val Space Consortium (VSC), Ciudad Politécnica de la Innovación, E-46022, Valencia, Spain.

B. Gimeno is with Department of Applied Physics, Universitat de València, 46100, Burjassot (Valencia), Spain.

D. Raboso is with European Space Research and Technology Centre of the European Space Agency (ESTEC-ESA), Noordwijk, The Netherlands.
Teflon ${ }^{\circledR}$ (PTFE) [1]. Conventional planar antennas are another example of the practical use of Teflon ${ }^{\circledR}$-based substrates, like Rogers RT5870®, which is able to withstand the environmental conditions of outer space. In [2], a compact single-layer patch antenna is designed for the HORYU-IV nanosatellite S-band communication link. This material presents good behaviour up to the millimeter-wave frequency range, i.e. the Ka-band (26-40 GHz), and will be widely used in new-generation communication satellites [3]. Many other dielectric materials can also be found in payload equipment.

Alumina $\left(\mathrm{Al}_{2} \mathrm{O}_{3}\right)$, for instance, a white and opaque ceramic material, is used in RF-windows for high-power klystrons to isolate the vacuum inside the tubes, and to allow the RF power to go through with a minimum of transmission losses [4], [5]. Alumina disks are also used as dielectric resonators, with a very high quality factor (Q), [6]. Alumina substrates can also be found in $\mathrm{C}$-band filters realized in microstrip technology [7]. Rohacell ${ }^{\circledR}$ foam composite is also widely used in the sandwich structures in many space applications, such as antennas and radomes, for the protection of radar equipment, aerospace components, launch vehicles, and other payloads [8]. Ultem ${ }^{\circledR} 1000$ with flight grade has a very low flammability and low levels of smoke evolution during combustion, thus making it very suitable for electrical and electronic insulators [9]. It is also possible to find Ultem resins for additive manufacturing processes (e.g. Ultem 9085 from Stratasys).

Furthermore, to avoid potential RF discharge under vacuum conditions in microwave filters, resonators are protected with dielectric materials. Rexolite is a good candidate, since it has a high dielectric strength of $20 \mathrm{kV} / \mathrm{mm}$ and a low loss tangent $\left(\tan \delta=5 \cdot 10^{-4}\right)$. In this context, [10] describes a high power comb-line diplexer where the filter resonators are completely or partially loaded with Rexolite. Similarly, the empty space inside helical resonators can be filled with Rexolite, thus minimizing the multipactor effect, and significantly increasing the power handling capability of helical filters [11].

However, due to the extreme environmental conditions of outer space, all payload equipment is required to comply with the very stringent requirements of space qualification [12]. In particular, RF and microwave equipment operating in outer space are prone to suffer multipactor discharge. This phenomenon must, therefore, be studied very carefully when dielectric materials are used. Multipactor effects occur in microwave devices under high vacuum and high power conditions, when an electron avalanche is caused by secondary 
electron emission driven by the Radio Frequency (RF) electromagnetic field [13]. The phenomenon depends on the applied RF power level, the geometry of the device considered, and, of course, the materials involved [14]. Multipactor can cause increased losses and/or RF signal distortion, and even physical damages [15], [16]. Most researches have studied the multipactor problem using the classic parallel plate configuration, firstly proposed in [17] and widely used later in multipactor research [13], [18], [19] and industry standards [20], [21].

Furthermore, the presence of dielectric materials in space hardware introduces additional effects and uncertainties (i.e. aging, outgassing) that should also be investigated. Until now, however, the multipactor effect of only very few dielectric materials has been analyzed using the very simple parallel plate model, where only 2D partially filled structures have been considered [22], [23]. In [24] the analysis has been performed taking also into account space-charge effects in the presence of time varying fields. The calculation of the electrostatic field due to a charge distribution on the dielectric in a dielectric-loaded rectangular waveguide has also been recently studied in [25].

In this context, initial results involving limited electromagnetic simulations of a new low-pass coaxial waveguide component using Teflon have been reported in [26]. The objective of this paper is to significantly extend the initial results presented in [26]. In this extended version, a sophisticated approach, based on an Electron Tracking Code (ETC) [27]), has been used to model multipaction breakdown of dielectric materials in more complex and realistic 3D geometries. Furthermore, more practical details about the design of the wideband low-pass coaxial filters are provided, including also the design of specific test hardware for five additional dielectric materials (Alumina, Rexolite, Rogers 5870, Rohacell and Ultem 1000). The six prototypes are first designed and characterized, in terms of their multipaction breakdown levels, using an ETC software tool and the real 3D electromagnetic fields within the dielectric-loaded structures. In addition to simulations, several multipactor measurement campaigns have also been performed in the L- and S-bands. The results obtained are reported in this paper thus providing, for the first time (to the authors' knowledge), a set of real experimental data for six dielectric materials widely employed in space applications.

\section{Dielectric Test DeVice}

\section{A. Device Description}

Our aim is to characterize the multipactor behavior of the dielectric materials described in Table I, namely, Alumina, Rexolite, Rogers RT5870, Rohacell, Teflon and Ultem 1000. Furthermore, the characterization is carried out from $1 \mathrm{GHz}$ to $4 \mathrm{GHz}$ (L- and S-bands), which is indeed a wide frequency range. The basic topology chosen for the Dielectric Test Device (DTD) is, therefore, based on the wideband coaxial stepped impedance structure shown in Fig. 1. The central section of the DTD is where the electric field will have the highest intensity. It is, therefore, the ideal location to place the dielectric materials under test. The dielectric samples will be glued in the central part of the low-pass filter (a low impedance section of the coaxial structure).

TABLE I

\begin{tabular}{|c|c|c|c|}
\hline \multicolumn{2}{|c|}{ LIST OF THE DIELECTRIC MATERIALS CONSIDERED IN THIS WORK. } & $\begin{array}{c}\text { Thermal } \\
\text { Conductivity } \\
\text { Dielectric Material }\end{array}$ & $\begin{array}{c}\text { Relative } \\
\text { dielectric } \\
\text { Permittivity }\end{array}$ \\
\hline Alumina & $\sim 10$ & 0.0002 & 30.3 \\
\hline Rexolite & 2.5 & 0.0005 & 0.18 \\
\hline Rogers RT5870 & 2.3 & 0.0005 & 0.22 \\
\hline Rohacell & 1.046 & 0.0017 & 0.033 \\
\hline Teflon & 2.1 & 0.0003 & 0.25 \\
\hline Ultem 1000 & $3-3.8$ & $0.001-0.005$ & 0.23 \\
\hline
\end{tabular}

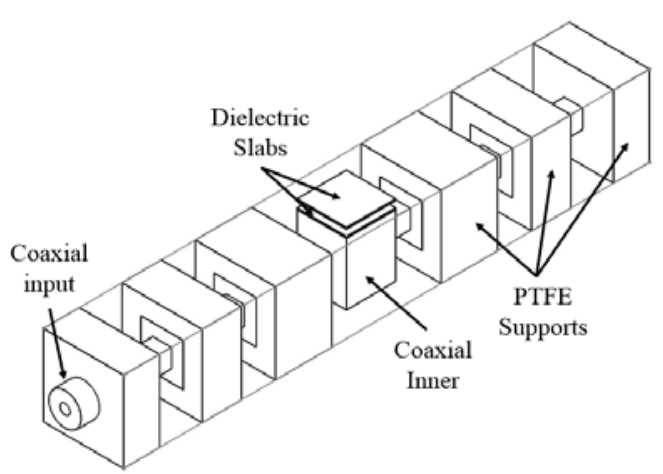

(a)

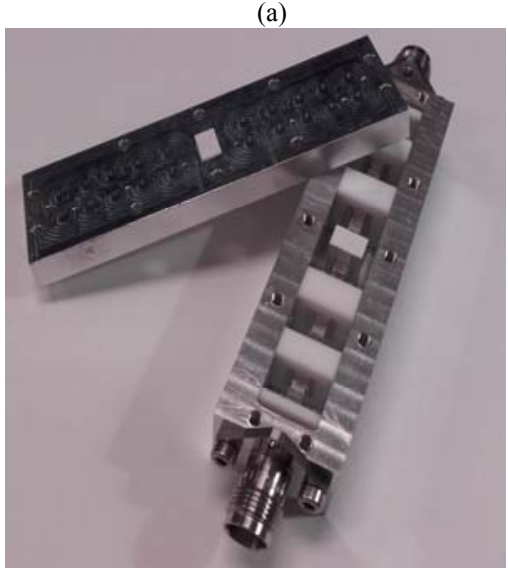

(b)

Fig. 1. Dielectric Test Device. (a) 3D-view of the stepped impedance low-pass filter. (b) Manufactured prototype.

Two samples will be used for the characterization of each dielectric material. One of the samples will be placed on top of the inner conductor, and the other will be placed on the opposite (outer) conductor surface, with a gap of $1 \mathrm{~mm}$ between the two samples (see details in Fig. 2). 
In order to design the DTD (see longitudinal view in Fig. 3) with enough accuracy and efficiently, a full-wave electromagnetic (EM) analysis tool was needed. The commercial software FEST3D v2018 (Aurora Software and Testing S.L.U., now with CST/3DS), based on the integral equation technique [28], was therefore chosen to accomplish this task.

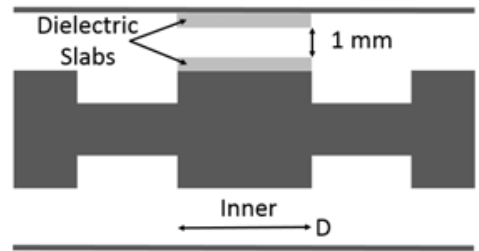

(a)

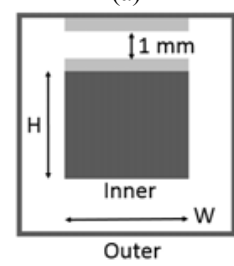

(b)

Fig. 2. Dielectric samples (slabs) over inner and outer conductors of the coaxial central section with a gap of $1 \mathrm{~mm}$. (a) Side view of the central stage, (b) Front view of the central stage.

However, although FEST3D can indeed perform very efficient full-wave simulations, it can only analyze structures composed of waveguide sections with uniform dielectric filling. In our case, the central part of the DTD is a nonuniform waveguide section. This problem has been solved in this paper by using the concept of the "effective dielectric constant" (EDC), previously applied to other non-uniform dielectric waveguide structures for millimeter-wave applications in [29].

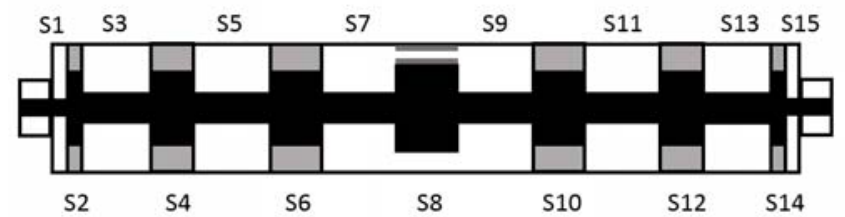

Fig. 3. Longitudinal view of the coaxial filter with dielectric slabs (located in section S8) in the central section. Low impedance sections (S2, S4, S6, S10, $\mathrm{S} 12$ and S14) are surrounded with Teflon, holding the inner conductor.

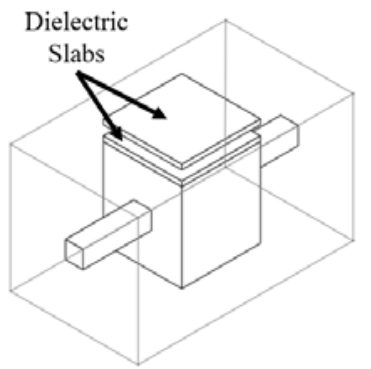

(a)

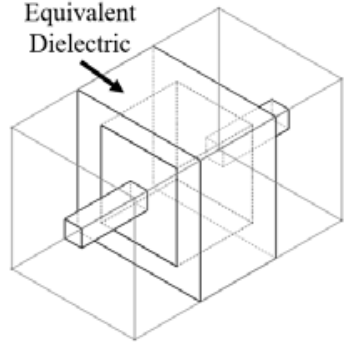

(b)

Fig. 4. (a) 3D view of the real central element with the two dielectric slabs (analyzed with CST Microwave Studio), and (b) 3D view of the central element with the EDC material filling the whole volume (analyzed with FEST3D).

In our case, the basic concept behind the EDC approach is to find the dielectric constant of an equivalent dielectric material that "fills" the same volume completely, and produces the same electrical performance of the non-uniform dielectric section, as seen from the corresponding input and output ports. The needed computations are carried out using a full-wave numerical simulator, in our case CST Microwave Studio v2018 (CST/3DS), to obtain the response of the real central element to be used as a reference, and FEST3D, for the fullwave analysis of the equivalent uniform section.

TABLE II

RELATIVE AND EFFECTIVE DIELECTRIC CONSTANTS (OBTAINED IN THIS PAPER) FOR PARALLEL SLABS

\begin{tabular}{|c|c|c|c|}
\hline Material & $\boldsymbol{\varepsilon}$ & $\boldsymbol{\varepsilon}_{\text {eff }}$ & $\begin{array}{c}\text { Slab } \\
\text { thickness } \\
(\mathbf{m m})\end{array}$ \\
\hline Alumina & 9.800 & 1.1384 & 0.250 \\
\hline Rexolite & 2.500 & 1.1083 & 0.500 \\
\hline Rogers RT5870 & 2.300 & 1.0712 & 0.256 \\
\hline Rohacell & 1.046 & 1.0002 & 1.000 \\
\hline Teflon & 2.100 & 1.0870 & 0.500 \\
\hline Ultem 1000 & 3.000 & 1.1795 & 0.900 \\
\hline
\end{tabular}

In Fig. 4 we can see the two structures used to obtain the EDC for each dielectric sample. Fig. 5 shows the differences between the responses considering the real dielectric material (in this case Alumina slabs), and the one with the corresponding EDC uniform material. Note that the difference between the values obtained is less than $0.3 \mathrm{~dB}$ in the whole frequency range. Table II summarizes the values of the relative $\left(\varepsilon_{\mathrm{r}}\right)$ and effective $\left(\varepsilon_{\mathrm{eff}}\right)$ dielectric constants (EDCs) obtained for all the materials considered in this study, as well as the slab thickness of each real sample. 


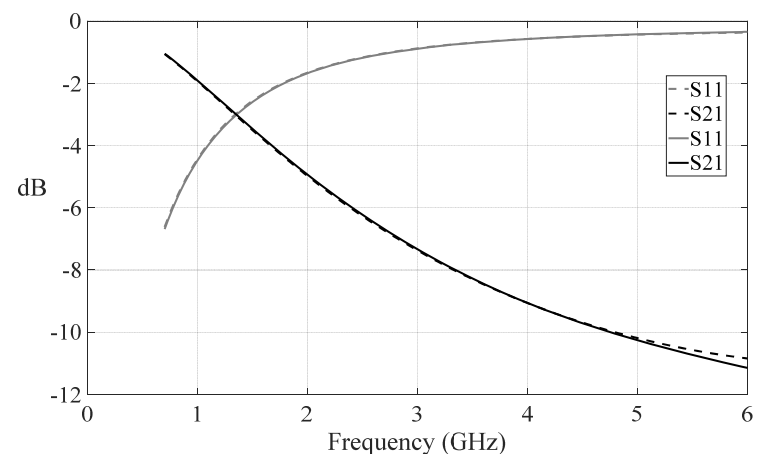

(a)

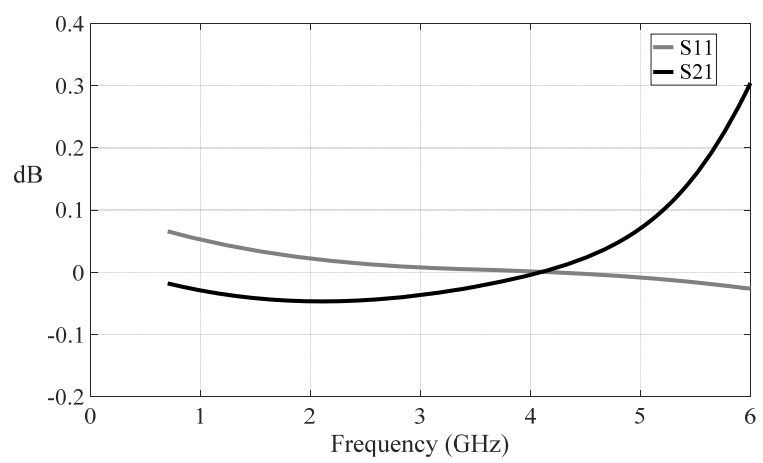

(b)

Fig. 5. (a) S11 and S21 parameters of real dielectric (lines) structure versus equivalent dielectric (dots) structure for Alumina, (b) difference between the amplitudes (in $\mathrm{dB}$ ) of the previous results for S11 (grey line) and S21 (black line) in (b)

Finally, it is important to note that all other low impedance sections of DTDs (where the metals of the inner and outer conductors are closer to each other) are fully loaded with Teflon (see S2, S4, S6, S10, S12 and S14 sections in Fig. 3), so that the multipactor effect cannot take place there. This will ensure that multipactor discharge will always happen in the central sections, where the dielectric samples are located. The high impedance sections can be left without Teflon filling, since the inner and outer conductors are sufficiently separated so that multipaction will certainly not take place there.

\section{B. Design Process}

The design of the DTDs is based on the EDC concept described in the previous paragraphs, and on the extensive use of FEST3D. The numerical tool CST Microwave Studio has also been used for validating the results provided by FEST3D. The design procedure is briefly summarized in the next paragraphs.

First, the normalized $g$ values for an equiripple low-pass filter prototype, with in-band return losses better than $20 \mathrm{~dB}$, are computed as detailed in [30], [31]. Then, the values for the lumped elements (inductors and capacitors) of a ladder filter implementation, have been computed. For this purpose, considering the corresponding frequency transformation and impedance scaling, the following expressions must be evaluated:

$$
\begin{gathered}
L_{n}=\frac{Z_{0} g_{n}}{2 \pi f_{c}} \\
C_{n}=\frac{g_{n}}{Z_{0} 2 \pi f_{c}}
\end{gathered}
$$

where the cutoff frequency of our desired low-pass response is chosen to be $f_{c}=5.3 \mathrm{GHz}$, and a characteristic impedance $\mathrm{Z}_{0}$ of $50 \Omega$ is chosen for the input and output ports. The values of the lumped elements obtained are displayed in Table III.

\begin{tabular}{|c|c|c|}
\hline 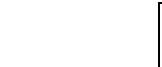 & $\begin{array}{c}\text { Prototype } \\
\text { Element }\end{array}$ & Element Value \\
\hline & L1 & $1.8169 \mathrm{nH}$ \\
\hline & $\mathrm{C} 2$ & $0.8775 \mathrm{pF}$ \\
\hline & L3 & $3.2522 \mathrm{nH}$ \\
\hline & $\mathrm{C} 4$ & $0.9886 \mathrm{pF}$ \\
\hline & L5 & $3.3930 \mathrm{nH}$ \\
\hline & C6 & $1.0075 \mathrm{pF}$ \\
\hline & L7 & $3.4239 \mathrm{nH}$ \\
\hline & $\mathrm{C} 8$ & $1.0113 \mathrm{pF}$ \\
\hline
\end{tabular}

TABLE III

From a practical point of view, the various inductances and capacitances can be implemented with uniform sections of high and low impedance transmission lines. In particular, in our DTD we have chosen to implement them with coaxial waveguide sections with smaller and bigger inner conductors of appropriate lengths.

Once the characteristic impedance of each rectangular coaxial section is obtained, as indicated in [32], the initial set of values for the lengths of all coaxial waveguides needed can be easily found using the following equations:

$$
\begin{gathered}
l_{n}=\frac{L_{n} c_{O}}{Z_{H}} ; \forall n \text { odd } \\
l_{n}^{\prime}=C_{n} v_{P T F E} Z_{L} ; v_{P T F E}=\frac{c_{O}}{\sqrt{\varepsilon_{r}}} ;\left\{\begin{array}{c}
\forall n \text { even } \\
n \neq 8
\end{array}\right. \\
l_{8}^{\prime}=C_{8} v_{8} Z_{8} ; v_{8}=\frac{c_{O}}{\sqrt{\varepsilon_{e f f}}}
\end{gathered}
$$

where $c_{O}$ is the speed of light in vacuum, and the values of $Z_{H}$ and $Z_{L}$ are recovered in this case with FEST3D. In equations (3) to (5), $l_{n}$ and $l_{n}^{\prime}$ are the corresponding lengths of each uniform coaxial waveguide implementing the inductances and capacitors, respectively, of the lumped element filter. The length of the central section (i.e. $l_{8}^{\prime}$ ) is obtained using the corresponding EDC value for the $\varepsilon_{\text {eff }}$ of each sample (see Table II).

In all DTDs designed, the dimensions for all outer conductors, and inner conductors of all high impedance sections, are kept fixed at $13 \times 13 \mathrm{~mm}$, and $3 \times 3 \mathrm{~mm}$, respectively. On the other hand, for the evaluation of (3)-(5), 
the square cross-section of the inner conductor of all low impedance sections is chosen to be of $6.5 \times 6.5 \mathrm{~mm}$, thus providing the initial length values included in Table IV for each DTD. Note that the first and the last sections (S1 and S15 in Table IV) of each DTD have an inner conductor with circular geometry (with a diameter $\phi$ of $1.64 \mathrm{~mm}$ ). This is because the inner conductor of the $\mathrm{S} 1$ and $\mathrm{S} 15$ sections is chosen to be equal to the inner conductor of the TNC connectors used as input and output ports for each DTD.

TABLE IV

INITIAL AND OPTIMIZED DIMENSIONS OF THE INNER CONDUCTOR SECTIONS, WHERE S IS SECTION, D DEPTH, W WIDTH, H HEIGHT AND $\Phi$ DIAMETER

\begin{tabular}{|c|c|c|}
\hline $\begin{array}{c}\text { ALUMINA } \\
\text { SECTIONS }\end{array}$ & $\begin{array}{c}\text { INITIAL } \\
\mathbf{D} \times \mathbf{W} \times \mathbf{H}(\mathbf{m m})\end{array}$ & $\begin{array}{c}\text { OPTIMIZED } \\
\mathbf{D} \times \mathbf{W} \times \mathbf{H}(\mathbf{m m})\end{array}$ \\
\hline S1 \& S15 & $5.88 \times \phi 1.64$ & $1.50 \times \phi 1.64$ \\
\hline S2 \& S14 & $4.65 \times 6.50 \times 6.50$ & $2.10 \times 6.69 \times 6.69$ \\
\hline S3 \& S13 & $11.72 \times 3.00 \times 3.00$ & $7.16 \times 3.00 \times 3.00$ \\
\hline S4 \& S12 & $5.23 \times 6.50 \times 6.50$ & $5.89 \times 6.69 \times 6.69$ \\
\hline S5 \& S11 & $12.23 \times 3.00 \times 3.00$ & $7.36 \times 3.00 \times 3.00$ \\
\hline S6 \& S10 & $5.33 \times 6.50 \times 6.50$ & $7.05 \times 6.69 \times 6.69$ \\
\hline S7 \& S9 & $12.34 \times 3.00 \times 3.00$ & $7.54 \times 3.00 \times 3.00$ \\
\hline S8 & $4.79 \times 8.00 \times 10.00$ & $5.00 \times 8.00 \times 10.00$ \\
\hline
\end{tabular}

\begin{tabular}{|c|c|c|}
\hline $\begin{array}{c}\text { REXOLITE } \\
\text { SECTIONS }\end{array}$ & $\begin{array}{c}\text { INITIAL } \\
\mathbf{D} \times \mathbf{W} \times \mathbf{H}(\mathbf{m m})\end{array}$ & $\begin{array}{c}\text { OPTIMIZED } \\
\mathbf{D} \times \mathbf{W} \times \mathbf{H}(\mathbf{m m})\end{array}$ \\
\hline S1 \& S15 & $5.88 \times \phi 1.64$ & $1.5 \times \boldsymbol{\phi} 1.64$ \\
\hline S2 \& S14 & $4.63 \times 6.50 \times 6.50$ & $1.75 \times 6.78 \times 6.78$ \\
\hline S3 \& S13 & $11.72 \times 3.00 \times 3.00$ & $6.84 \times 3.00 \times 3.00$ \\
\hline S4 \& S12 & $5.22 \times 6.50 \times 6.50$ & $5.26 \times 6.78 \times 6.78$ \\
\hline S5 \& S11 & $12.23 \times 3.00 \times 3.00$ & $7.13 \times 3.00 \times 3.00$ \\
\hline S6 \& S10 & $5.32 \times 6.50 \times 6.50$ & $6.25 \times 6.78 \times 6.78$ \\
\hline S7 \& S9 & $12.34 \times 3.00 \times 3.00$ & $7.04 \times 3.00 \times 3.00$ \\
\hline S8 & $5.94 \times 8.00 \times 9.00$ & $6.50 \times 8.00 \times 9.00$ \\
\hline
\end{tabular}

\begin{tabular}{|c|c|c|}
\hline $\begin{array}{c}\text { ROGERS } \\
\text { RT5870 } \\
\text { SECTIONS }\end{array}$ & $\begin{array}{c}\text { INITIAL } \\
\mathbf{D} \times \mathbf{W} \times \mathbf{H}(\mathbf{m m})\end{array}$ & $\begin{array}{c}\text { OPTIMIZED } \\
\mathbf{D} \times \mathbf{W} \times \mathbf{H}(\mathbf{m m})\end{array}$ \\
\hline S1 \& S15 & $5.88 \times \boldsymbol{\phi} 1.64$ & $2.5 \times \boldsymbol{\phi} 1.64$ \\
\hline S2 \& S14 & $4.64 \times 6.50 \times 6.50$ & $3.31 \times 6.88 \times 6.88$ \\
\hline S3 \& S13 & $11.72 \times 3.00 \times 3.00$ & $6.94 \times \times 3.00 \times 3.00$ \\
\hline S4 \& S12 & $5.22 \times 6.50 \times 6.50$ & $6.37 \times 6.88 \times 6.88$ \\
\hline S5 \& S11 & $12.23 \times 3.00 \times 3.00$ & $5.52 \times 3.00 \times 3.00$ \\
\hline S6 \& S10 & $5.32 \times 6.50 \times 6.50$ & $9.14 \times 6.88 \times 6.88$ \\
\hline S7 \& S9 & $12.34 \times 3.00 \times 3.00$ & $4.88 \times 3.00 \times 3.00$ \\
\hline
\end{tabular}

\begin{tabular}{|c|c|c|}
\hline S8 & $4.70 \times 8.00 \times 9.98$ & $8.00 \times 8.00 \times 9.98$ \\
\hline
\end{tabular}

\begin{tabular}{|c|c|c|}
\hline $\begin{array}{c}\text { ROHACELL } \\
\text { SECTIONS }\end{array}$ & $\begin{array}{c}\text { INITIAL } \\
\mathbf{D} \times \mathbf{W} \times \mathbf{H}(\mathbf{m m})\end{array}$ & $\begin{array}{c}\text { OPTIMIZED } \\
\mathbf{D} \times \mathbf{W} \times \mathbf{H}(\mathbf{m m})\end{array}$ \\
\hline S1 \& S15 & $5.88 \times \phi 1.64$ & $2.73 \times \phi 1.64$ \\
\hline S2 \& S14 & $4.64 \times 6.50 \times 6.50$ & $2.5 \times 6.91 \times 6.91$ \\
\hline S3 \& S13 & $11.72 \times 3.00 \times 3.00$ & $8.76 \times 3.00 \times 3.00$ \\
\hline S4 \& S12 & $5.22 \times 6.50 \times 6.50$ & $3.82 \times 6.91 \times 6.91$ \\
\hline S5 \& S11 & $12.23 \times 3.00 \times 3.00$ & $9.39 \times 3.00 \times 3.00$ \\
\hline S6 \& S10 & $5.32 \times 6.50 \times 6.50$ & $4.14 \times 6.91 \times 6.91$ \\
\hline S7 \& S9 & $12.34 \times 3.00 \times 3.00$ & $9.08 \times 3.00 \times 3.00$ \\
\hline S8 & $7.84 \times 8.00 \times 7.00$ & $8,00 \times 8.00 \times 7.00$ \\
\hline
\end{tabular}

\begin{tabular}{|c|c|c|}
\hline $\begin{array}{c}\text { TEFLON } \\
\text { SECTIONS }\end{array}$ & $\begin{array}{c}\text { INITIAL } \\
\mathbf{D} \times \mathbf{W} \times \mathbf{H}(\mathbf{m m})\end{array}$ & $\begin{array}{c}\text { OPTIMIZED } \\
\mathbf{D} \times \mathbf{W} \times \mathbf{H}(\mathbf{m m})\end{array}$ \\
\hline S1 \& S15 & $5.88 \times \phi 1.64$ & $2.04 \times \phi 1.64$ \\
\hline S2 \& S14 & $4.64 \times 6.50 \times 6.50$ & $2.66 \times 6.71 \times 6.71$ \\
\hline S3 \& S13 & $11.72 \times 3.00 \times 3.00$ & $7.25 \times 3.00 \times 3.00$ \\
\hline S4 \& S12 & $5.22 \times 6.50 \times 6.50$ & $5.31 \times 6.71 \times 6.71$ \\
\hline S5 \& S11 & $12.23 .00 \times 3.00 \times 3$ & $7.23 .00 \times 3.00 \times 3$ \\
\hline S6 \& S10 & $5.32 \times 6.50 \times 6.50$ & $6.38 \times 6.71 \times 6.71$ \\
\hline S7 \& S9 & $12.34 \times 3.00 \times 3.00$ & $7.12 \times 3.00 \times 3.00$ \\
\hline S8 & $6.05 \times 8.00 \times 9.00$ & $6.5 \times 8.00 \times 9.00$ \\
\hline
\end{tabular}

\begin{tabular}{|c|c|c|}
\hline $\begin{array}{c}\text { ULTEM } \\
\mathbf{1 0 0 0} \\
\text { SECTIONS }\end{array}$ & $\begin{array}{c}\text { INITIAL } \\
\mathbf{D} \times \mathbf{W} \times \mathbf{H}(\mathbf{m m})\end{array}$ & $\begin{array}{c}\text { OPTIMIZED } \\
\mathbf{D} \times \mathbf{W} \times \mathbf{H}(\mathbf{m m})\end{array}$ \\
\hline S1 \& S15 & $5.88 \times \phi 1.64$ & $2.50 \times \phi 1.64$ \\
\hline S2 \& S14 & $4.64 \times 6.50 \times 6.50$ & $2.50 \times 7.00 \times 7.00$ \\
\hline S3 \& S13 & $11.72 \times 3.00 \times 3.00$ & $8.06 \times 3.00 \times 3.00$ \\
\hline S4 \& S12 & $5.22 \times 6.50 \times 6.50$ & $4.35 \times 7.00 \times 7.00$ \\
\hline S5 \& S11 & $12.23 \times 3.00 \times 3.00$ & $8.16 \times 3.00 \times 3.00$ \\
\hline S6 \& S10 & $5.32 \times 6.50 \times 6.50$ & $5.08 \times 7.00 \times 7.00$ \\
\hline S7 \& S9 & $12.34 \times 3.00 \times 3.00$ & $7.62 \times 3.00 \times 3.00$ \\
\hline S8 & $7.84 \times 8.00 \times 7.40$ & $8.00 \times 8.00 \times 7.40$ \\
\hline
\end{tabular}

The initial solution obtained must then be optimized in order to obtain the desired DTD responses (S-parameters), considering as a reference the ideal response of the low-pass filter prototype. For this purpose, the Simplex method was used to minimize the error, using again FEST3D and the EDC concept for performing efficient full-wave simulations. The lengths of all coaxial waveguides, and the size of the inner conductor of the low impedance sections, have been used as optimization variables. The final values obtained are given in Table IV. 
The numerical tool CST Microwave Studio has then been used to verify the validity of the solution obtained considering the real structure with a non-uniform central section. In all DTDs, the optimal dimensions found with FEST3D were good enough. A fast fine refinement, performed again with FEST3D, was needed in only a few cases. Finally, the results from CST Microwave Studio have also been used (as detailed in section III.A) for the numerical evaluation of the multipactor effect.

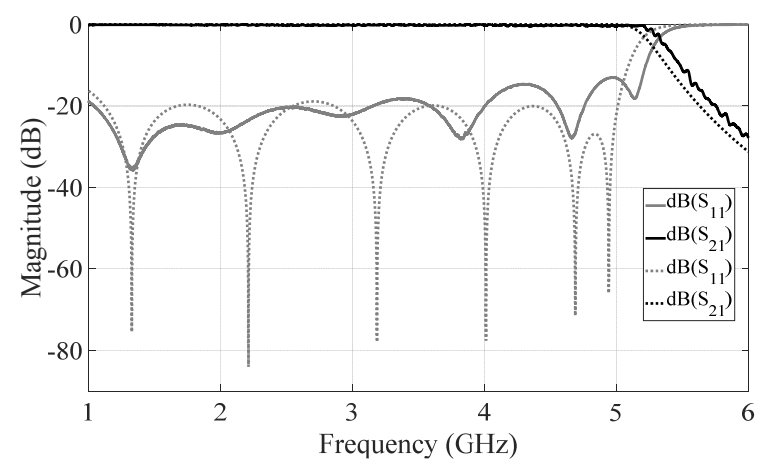

(a)

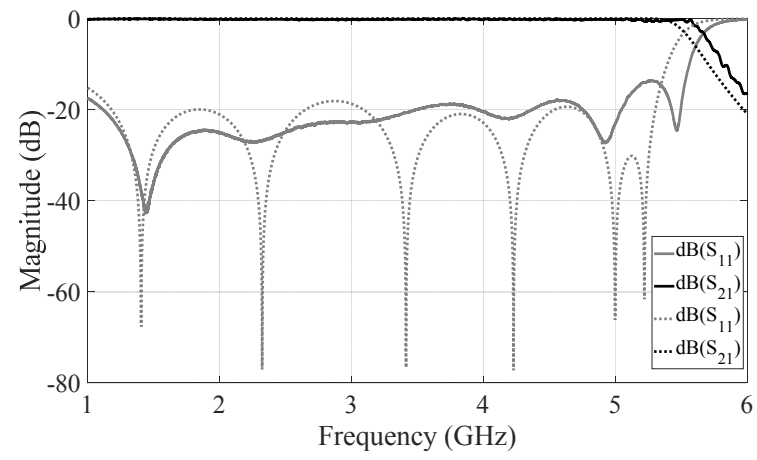

(b)

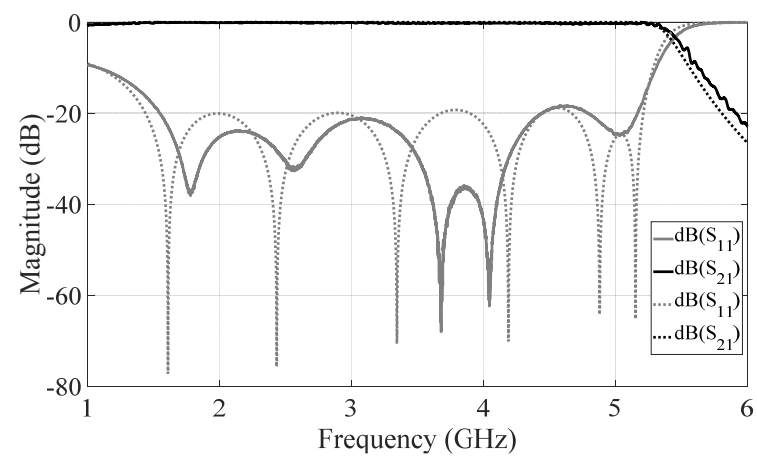

(c)

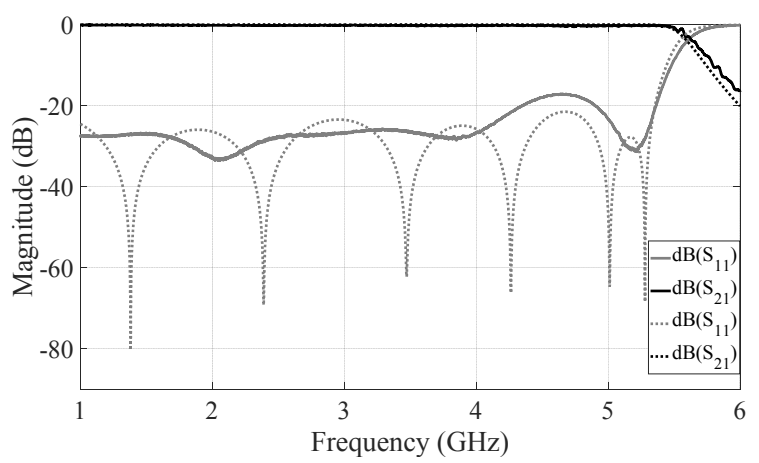

(d)

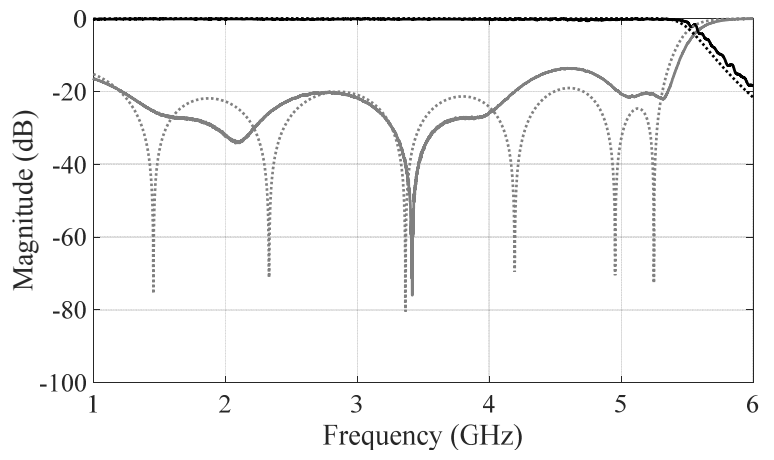

(e)

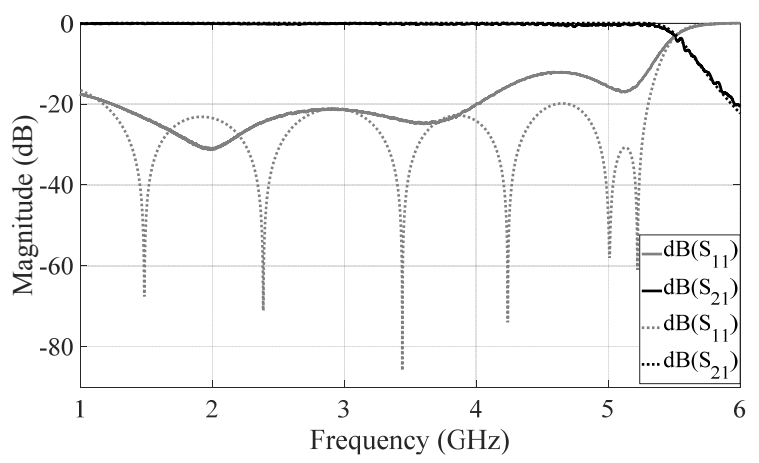

(f)

Fig. 6. Comparison between simulated and measured frequency responses for (a) Alumina, (b) Rexolite, (c) Rogers RT5870, (d) Rohacell, (e) Teflon and (f) Ultem 1000 DTDs. Dots are used for simulated data, and lines for the measurements. Return losses better than $18 \mathrm{~dB}$ from 1.5 to $4 \mathrm{GHz}$ in all the DTDs.

\section{Experimental Validation}

In Figs. 6 a) to $f$ ), we show the simulated versus experimental data of all DTDs manufactured, where perfect conductors have been considered in simulations, and prototypes are made of Aluminium. As we can see, all devices have a good matching level (below $20 \mathrm{~dB}$ ) from $1.3 \mathrm{GHz}$ to 4 $\mathrm{GHz}$, which is in good agreement with the experimental data (return losses better than $18 \mathrm{~dB}$ from 1.5 to $4 \mathrm{GHz}$ in all the DTDs). The differences observed are due to manufacturing tolerances (around $150 \mu \mathrm{m}$ ). It is important to note that the 
measured responses are all perfectly adequate for the multipactor characterization of the dielectric samples.

As it will be detailed in the next section, the RF power setup for performing the multipactor measurement campaign is designed to operate between 1.3 and $4 \mathrm{GHz}$. The multipactor measurements will therefore be carried out in this frequency range. All DTDs have a gap of $1 \mathrm{~mm}$ in their central regions. As a consequence, the frequency-gap product ranges from 1.3 $\mathrm{GHz} \times \mathrm{mm}$ to $4 \mathrm{GHz} \times \mathrm{mm}$, which is sufficient to characterize a considerable fraction of the multipactor susceptibility charts for all materials [17].

Using the software tool CST Microwave Studio, we have also computed the electric field distribution in the central region of the DTDs. As expected, the maximum value of the electric field is located between the two dielectric slabs (see Fig. 7 for the Rogers RT5870 dielectric case), thus ensuring that multipaction will occur there. Furthermore, as it will be detailed in next section, the multipactor simulation tool SPARK3D v2018 (Aurora Software and Testing S.L.U., $\mathrm{CST} / 3 \mathrm{DS}$ ) has been used to predict where the RF breakdown multipaction will actually occur, and with which RF input power level.
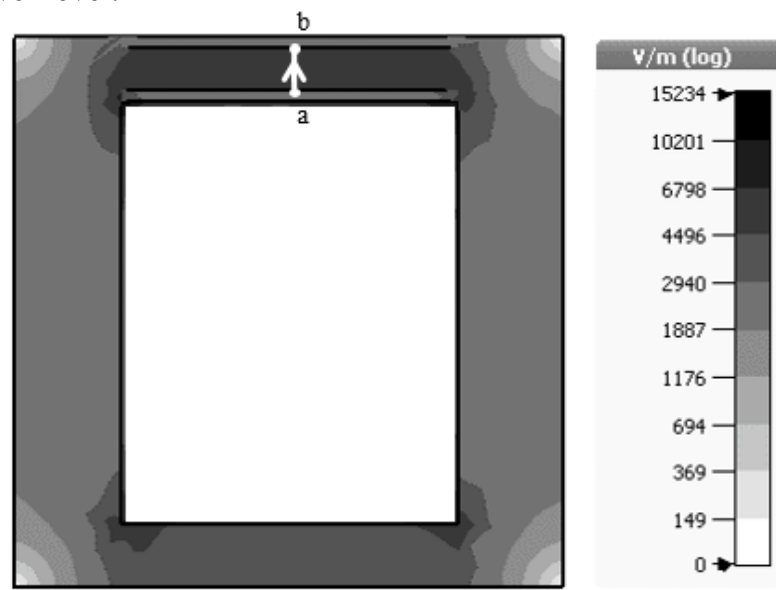

Fig. 7. Electric field distribution for the Rogers RT5870 DTD at $3.97 \mathrm{GHz}$, where the maximum electric field is located between the two dielectric slabs.

\section{MultipaCtOR CHARACTERIZATION}

\section{A. Simulation Results}

For the accurate multipactor analysis of the dielectric samples using an ETC code, it is necessary to obtain first the real electromagnetic (EM) field distribution inside the corresponding DTD at the frequency of operation. Electric and magnetic fields in vector forms have been exported from simulated data obtained with the CST software package, for their use in the ETC multipactor software tool SPARK3D.

In Fig. 8 we can see the distribution of the magnitude of the electric field in the whole volume of the central section of the DTD with Alumina dielectric samples. Note that the maximum value of the electric field is reached between the dielectric slabs. However, some fringing fields (with lower intensity) may also appear in some corners of the inner conductor.

The SPARK3D software is able to import the 3D EM fields from external solvers (CST Microwave Studio software in this case), and track the resulting electron motion by solving the 3D Lorentz force equation. SPARK3D models the electron interactions with the DTD surfaces, where they can be absorbed, reflected or may extract secondary electrons, following the Vaughan model [33]. The secondary electron emission angle and energy are random, with cosine law and Maxwellian distributions, respectively. Details on the SPARK3D physical models can be found in [34]. The number of initial electrons is an input parameter in SPARK3D. Typically this number is increased until reaching convergence. For the simulations in this paper, 1000 initial electrons have been used to ensure convergence. Given an imported 3D EM field mesh, SPARK3D performs a power sweep from which the electron population over time is computed. For each simulated power level, a multipactor discharge is automatically detected if the electrons follow an exponential growth beyond certain predefined limit.

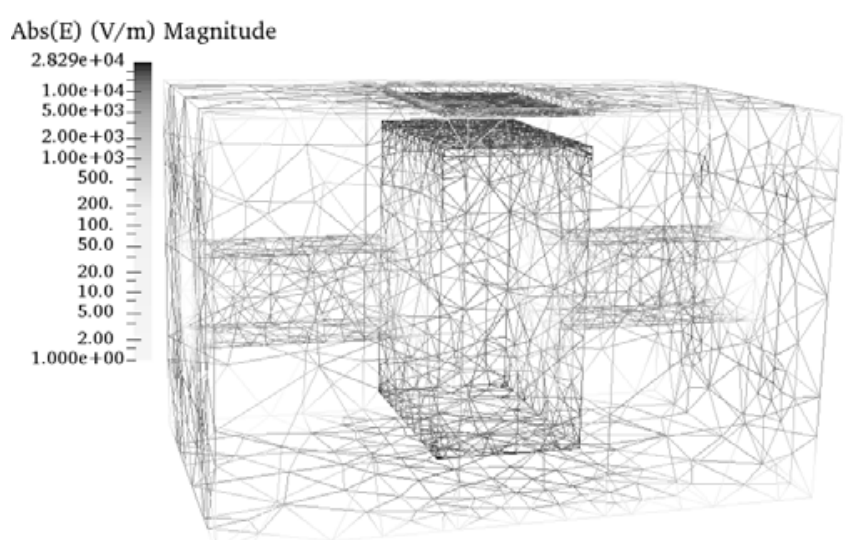

Fig. 8. Distribution of the magnitude of the electric field in the central part of the Alumina DTD for a working frequency of $1.3 \mathrm{GHz}$ and an input power of $1 \mathrm{~W}$. The maximum electric field is in between dielectric slabs and corners.

TABLE V

\begin{tabular}{|c|c|c|c|}
\hline \multicolumn{1}{|c|}{ SEY Parameters USED IN MULTIPACTOR SimUlations [21] } \\
\hline Standard Aluminium & $\mathbf{E}_{\mathbf{1}}(\mathbf{e V})$ & $\mathbf{E}_{\mathbf{m a x}}(\mathbf{e V})$ & $\mathbf{S E Y}_{\max }$ \\
& 24 & 150 & 2.98 \\
\hline
\end{tabular}

Obviously, the multipactor phenomenon is material dependent. This is quantitatively accounted for with the Secondary Electron Yield (SEY) coefficient [33]. The energy level at which the SEY is unity corresponds to $E_{1}$, also called lower crossover electron energy. Usually, the $E_{1}$ parameter is the one with most influence in the multipactor breakdown threshold. When the SEY is maximum (SEY max $_{\text {, }}$, the corresponding impact energy is denoted as $\mathrm{E}_{\max }$.

In principle, each of the dielectric materials of this work should have its own SEY curve and SEY parameters. 
Unfortunately, however, the measurement of the SEY curve in dielectrics is rather complex, and tends to yield non-consistent values. This may be due to the surface charging process experimented during the testing activity, which affects the final result [35]. For this reason, the standard Aluminium SEY properties [21] have been used for all materials (see details in Table V).

The SEY properties of standard Aluminium are known to yield conservative multipactor predictions in most cases, and are typically used as a worst-case alternative, when dealing with materials having unknown SEY values. This is a standard practice followed by practitioners in the field [21]. Once the SEY values are introduced in SPARK3D, the software tool is able to provide the multipactor threshold levels, for each frequency of operation, in terms of the RF power at the input port of each DTD. The multipactor breakdown voltage between the two dielectric samples can then be represented in terms of the $f \times d$ product, thus obtaining the wanted susceptibility charts for each particular material.

The voltage between the two parallel (and close) dielectric slabs in the central section of the DTD can also be easily obtained through the line integral in (6). This numerical integration is performed from points $a$ to $b$ of Fig. 7, using the electric field previously obtained with CST Microwave Studio (considering a normalized RF input power of $1 \mathrm{~W}$ ).

$$
V_{a b}=\int_{a}^{b} E d l
$$

Thus, according to Fig. 7, $V_{a b}$ is defined as the voltage in the gap at the central of the dielectric slabs. Although the electric field is expected to be non-uniform for this device, the difference of computing the voltage at the central or at other part of the gap is negligible, since the gap size of $1 \mathrm{~mm}$ is much smaller than the slab surface dimensions, and since the dielectric material tends to concentrate the electric field within the gap (see Fig. 8). The electric field can, therefore, be considered uniform in the area between the dielectric slabs.

The threshold voltage (defined in the central section of the DTD) for each particular material and $f \times d$ product can then be determined thanks to the quadratic relationship between the $\mathrm{RF}$ input power (provided by SPARK3D) and the values of $V_{a b}$. The data obtained for the six dielectric materials are collected in Table VI.

TABLE VI

RF MULTIPACTOR DISCHARGE SIMULATED RESULTS FOR ALL MATERIALS

\begin{tabular}{|c|c|c|c|}
\hline \multirow{2}{*}{$\begin{array}{c}\text { Frequency } \\
(\mathbf{G H z})\end{array}$} & $\begin{array}{c}\text { V at 1W } \\
\text { (V) }\end{array}$ & $\begin{array}{c}\text { Threshold } \\
\text { (W) }\end{array}$ & $\begin{array}{c}\text { Threshold } \\
\text { (V) }\end{array}$ \\
\hline 1.3 & 7.94 & 48 & 54,70 \\
\hline 1.6 & 8.21 & 96 & 80,17 \\
\hline 2.0 & 8.8 & 191 & 121,93 \\
\hline 2.5 & 9.14 & 215 & 132,69 \\
\hline 3.0 & 9.1 & 273 & 151,03 \\
\hline 3.5 & 9.82 & 289 & 166,13 \\
\hline 3.97 & 11,1 & 289 & 188,99 \\
\hline
\end{tabular}

\begin{tabular}{|c|c|c|c|}
\hline \multirow{2}{*}{$\begin{array}{c}\text { Frequency } \\
(\mathbf{G H z})\end{array}$} & \multicolumn{3}{|c|}{ REXOLITE } \\
\cline { 2 - 4 } & V at 1W & Threshold(W) & Threshold(V) \\
\hline 1.3 & 5.95 & 88 & 55,74 \\
\hline 1.6 & 6.09 & 191 & 84,18 \\
\hline 2.0 & 6.48 & 383 & 126,91 \\
\hline 2.5 & 6.83 & 703 & 179,15 \\
\hline 3.0 & 6.77 & 672 & 177,18 \\
\hline 3.5 & 6.96 & 765 & 192,11 \\
\hline 3.97 & 7.72 & 734 & 208,96 \\
\hline
\end{tabular}

\begin{tabular}{|c|c|c|c|}
\hline \multirow{2}{*}{$\begin{array}{c}\text { Frequency } \\
(\mathbf{G H z})\end{array}$} & \multicolumn{3}{|c|}{ ROGERS 5870 } \\
\cline { 2 - 4 } & V at 1W & Threshold(W) & Threshold(V) \\
\hline 1.3 & 6.01 & 96 & 56,32 \\
\hline 1.6 & 6.03 & 207 & 83,71 \\
\hline 2.0 & 6.48 & 398 & 125,52 \\
\hline 2.5 & 7.26 & 672 & 179,60 \\
\hline 3.0 & 7.33 & 609 & 171,73 \\
\hline 3.5 & 7.28 & 734 & 189,53 \\
\hline 3.97 & 8.05 & 672 & 204,96 \\
\hline
\end{tabular}

\begin{tabular}{|c|c|c|c|}
\hline \multirow{2}{*}{$\begin{array}{c}\text { Frequency } \\
\text { (GHz) }\end{array}$} & \multicolumn{3}{|c|}{ ROHACELL } \\
\cline { 2 - 4 } & V at 1W & Threshold(W) & Threshold(V) \\
\hline 1.3 & 3.28 & 289 & 55,58 \\
\hline 1.6 & 3.27 & 672 & 84,67 \\
\hline 2.0 & 3.33 & 1406 & 125,04 \\
\hline 2.5 & 3.48 & 2562 & 176,44 \\
\hline 3.0 & 3.54 & 2312 & 169,24 \\
\hline 3.5 & 3.53 & 2937 & 191,68 \\
\hline 3.97 & 3,72 & 3062 & 205,57 \\
\hline
\end{tabular}

\begin{tabular}{|c|c|c|c|}
\hline \multirow{2}{*}{$\begin{array}{c}\text { Frequency } \\
(\mathbf{G H z})\end{array}$} & \multicolumn{3}{|c|}{ TEFLON } \\
\cline { 2 - 4 } & V at 1W & Threshold(W) & Threshold(V) \\
\hline 1.3 & 5.7 & 100 & 56,81 \\
\hline 1.6 & 5.79 & 215 & 84,69 \\
\hline 2.0 & 6.09 & 430 & 126,43 \\
\hline 2.5 & 6.44 & 765 & 178,38 \\
\hline 3.0 & 6.47 & 703 & 171,02 \\
\hline 3.5 & 6.63 & 828 & 190,20 \\
\hline 3.97 & 7.28 & 859 & 213,61 \\
\hline
\end{tabular}

\begin{tabular}{|c|c|c|c|}
\hline \multirow{2}{*}{$\begin{array}{c}\text { Frequency } \\
\text { (GHz) }\end{array}$} & \multicolumn{3}{|c|}{ ULTEM 1000 } \\
\cline { 2 - 4 } & V at 1W & Threshold(W) & Threshold(V) \\
\hline 1.3 & 5.48 & 107 & 56,73 \\
\hline 1.6 & 5.51 & 230 & 83,60 \\
\hline 2.0 & 5.74 & 492 & 127,47 \\
\hline 2.5 & 6.13 & 890 & 182,94 \\
\hline 3.0 & 6.25 & 734 & 169,07 \\
\hline 3.5 & 6.34 & 922 & 192,05 \\
\hline 3.97 & 6.89 & 922 & 208,93 \\
\hline
\end{tabular}

Next, the classical susceptibility charts for each of the six dielectric samples considered in this work have been computed (see Fig. 9). In all the charts, the RF voltage breakdown refers to the central section of each DTD, where two parallel dielectric slabs are located with a gap $d=1 \mathrm{~mm}$, and frequencies between $1.3 \mathrm{GHz}$ and $4 \mathrm{GHz}$ have been considered.

\section{B. Experimental Results}

An experimental test campaign has also been carried out, at the RF High Power facility of Val Space ConsortiumEuropean Space Agency (VSC-ESA), in order to validate the simulated results, and also provide more realistic data of solid engineering value. A standard experimental set-up for multipactor measurements (see [20] for a more detailed 
description) was assembled. The RF signal generator was operated in pulsed mode with a pulse width of $20 \mu \mathrm{s}$, corresponding to a duty cycle of $2 \%$. A radioactive source (Strontium-90) with a strength of $1 \mathrm{mCi}$ was employed for electron seeding purposes. The source was placed just above (slightly before or after) the physical location of the dielectric sample (dielectric slabs) in the component, near the top cover, and focusing one of the venting holes, with the objective of helping the electrons generated to get into the central section where dielectric material is located. For the multipactor measurements high vacuum condition (gas pressure) below $1.5 \times 10^{-5}$ mbar was reached.

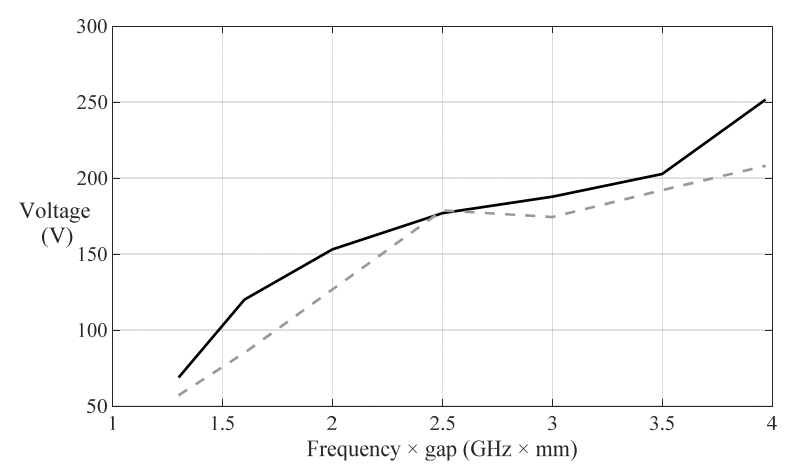

(a)

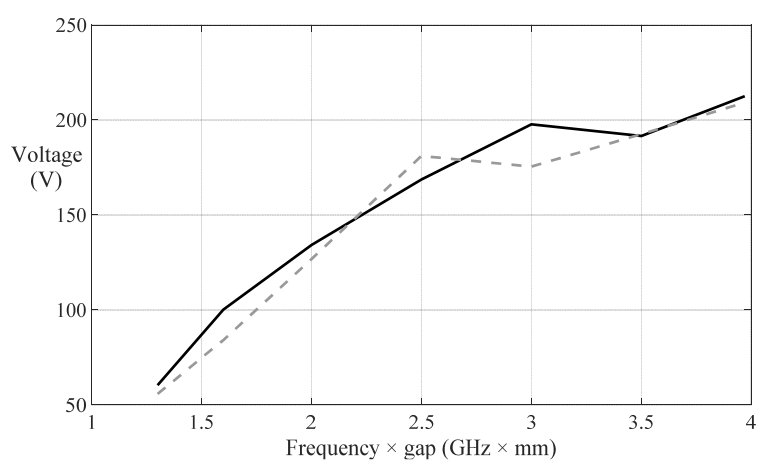

(b)

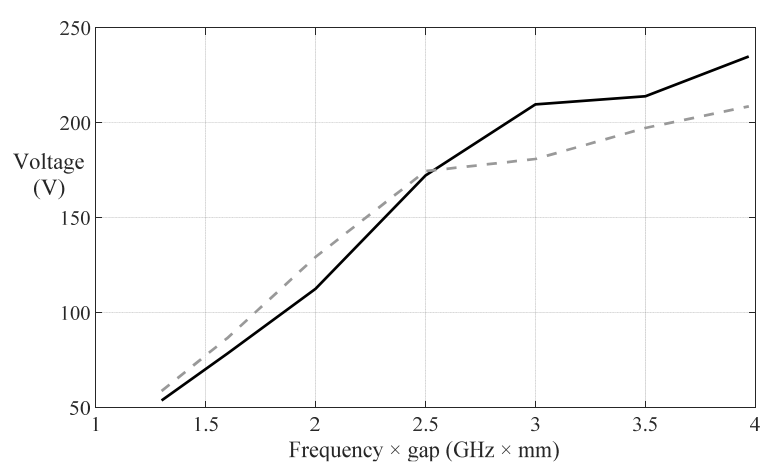

(c)

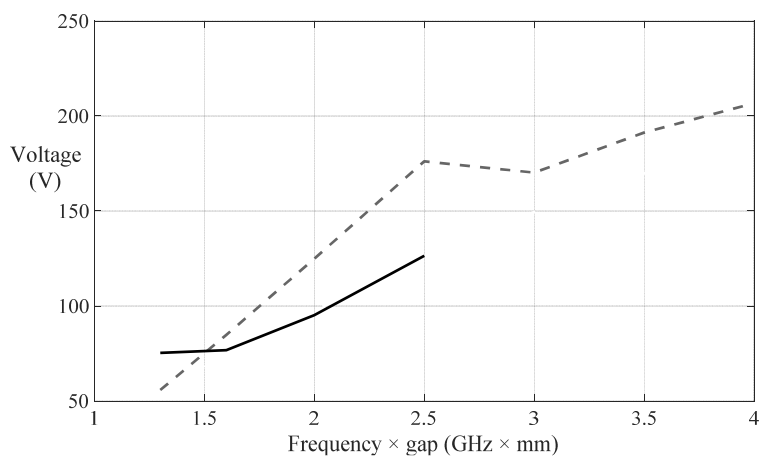

(d)

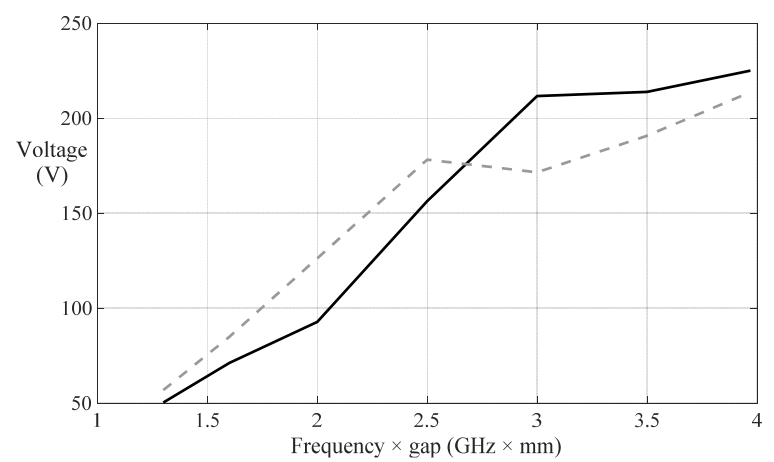

(e)

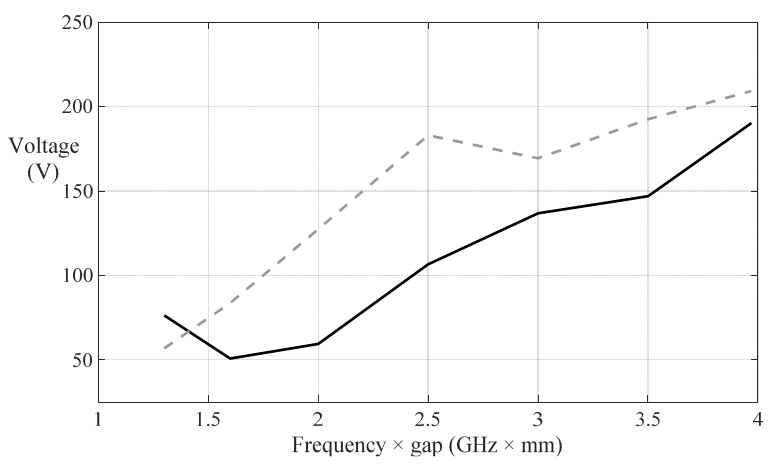

(f)

Fig. 9. Susceptibility charts (experimental results in line and simulated in dotted) for simulated for (a) Alumina, (b) Rexolite, (c) Rogers RT5870, (d) Rohacell, (e) Teflon and (f) Ultem 1000 dielectric materials considered in this work. Two parallel slabs are located in the central section of the DTD with a gap between them (i.e. $d$ ) of $1 \mathrm{~mm}$.

For each dielectric material, the corresponding DTD prototype has been tested. Measurements were performed at seven frequency points from $1.3 \mathrm{GHz}$ to $3.97 \mathrm{GHz}$, which correspond to a frequency-gap product $(f \times d)$ ranging from 1.3 $\mathrm{GHz} \times \mathrm{mm}$ to $3.97 \mathrm{GHz} \times \mathrm{mm}$. The $\mathrm{RF}$ power multipactor threshold value was measured at the input port of each DTD. In Fig. 9 and Table VII we compare the experimental results with the simulated ones, previously obtained with SPARK3D. 
The bottom of Table VII shows the different methods employed for detecting multipactor events. All results in Table VII have been obtained after at least two detection methods were triggered.

A reasonably good agreement between simulated and measured results is generally observed. The maximum differences between simulations and measurements are, in fact, bellow $3 \mathrm{~dB}$ for all cases considered, except for Rohacell and Ultem 1000. For Rohacell the measured results are given up to $2.5 \mathrm{GHz}$. For higher frequencies, there was not enough power available in the experimental set-up to trigger the discharge. In the case of Ultem 1000, besides the first frequency point, all the simulated values are above the test results, but with a difference below $3 \mathrm{~dB}$, except for the frequencies of $2.0 \mathrm{GHz}$ and $2.5 \mathrm{GHz}$, where the difference increases up to $5.6 \mathrm{~dB}$ and $4.2 \mathrm{~dB}$, respectively (as can be concluded from Table VII).

TABLE VII

\begin{tabular}{|c|c|c|}
\hline \multirow{2}{*}{$\begin{array}{c}\text { Frequency } \\
\text { (GHz) }\end{array}$} & \multicolumn{2}{|c|}{ ALUMINA } \\
\hline & Simulated(dBW) & Discharge(dBW) \\
\hline 1.3 & 17.1 & $18.8^{1,2,3,5}$ \\
\hline 1.6 & 20.3 & $23.3^{\mathbf{1 , 2 , 3 , 4 , 5}}$ \\
\hline 2.0 & 23.2 & $24.8^{1,2,3,4,5}$ \\
\hline 2.5 & 25.8 & $25.7^{1,3,4,5}$ \\
\hline 3.0 & 25.6 & $26.3^{1,2}$ \\
\hline 3.5 & 25.8 & $26.3^{1,2,3}$ \\
\hline 3.97 & 25.5 & $27.1^{1,2,3}$ \\
\hline
\end{tabular}

\begin{tabular}{|c|c|c|}
\hline \multirow{2}{*}{$\begin{array}{c}\text { Frequency } \\
(\mathbf{G H z})\end{array}$} & \multicolumn{2}{|c|}{ REXOLITE } \\
\cline { 2 - 3 } & Simulated(dBW) & Discharge(dBW) \\
\hline 1.3 & 19.4 & $20.0^{\mathbf{1 , 2 , 5}}$ \\
\hline 1.6 & 22.8 & $24.3^{\mathbf{1 , 2 , 3}}$ \\
\hline 2.0 & 25.8 & $26.3^{\mathbf{1 , 2 , 3}}$ \\
\hline 2.5 & 28.5 & $27.9^{\mathbf{1 , 3 , 4}}$ \\
\hline 3.0 & 28.3 & $29.3^{\mathbf{1 , 2 , 3 , 4 , 5}}$ \\
\hline 3.5 & 28.8 & $28.8^{\mathbf{1 , 2 , 3 , 4},}$ \\
\hline 3.97 & 28.7 & $28.8^{\mathbf{1 , 2 , 3}}$ \\
\hline
\end{tabular}

\begin{tabular}{|c|c|c|}
\hline \multirow{2}{*}{$\begin{array}{c}\text { Frequency } \\
(\mathbf{G H z})\end{array}$} & \multicolumn{2}{|c|}{ ROGERS RT5870 } \\
\cline { 2 - 3 } & Simulated(dBW) & Discharge(dBW) \\
\hline 1.3 & 19.8 & $19.0^{\mathbf{1 , 2}}$ \\
\hline 1.6 & 23.2 & $22.3^{\mathbf{1 , 2 , 3 , 4 , 5}}$ \\
\hline 2.0 & 26.0 & $24.8^{\mathbf{1 , 2 , 3 , 4 , 5}}$ \\
\hline 2.5 & 28.3 & $27.5^{\mathbf{1 , 2 , 3 , 4 , 5}}$ \\
\hline 3.0 & 27.8 & $29.1^{\mathbf{1 , 2}}$ \\
\hline 3.5 & 28.7 & $29.4^{\mathbf{1 , 2 , 3 , 4 , 5}}$ \\
\hline 3.97 & 28.3 & $29.3^{\mathbf{1 , 2 , 3 , 4 , 5}}$ \\
\hline
\end{tabular}

\begin{tabular}{|c|c|c|}
\hline \multirow{2}{*}{$\begin{array}{c}\text { Frequency } \\
(\mathbf{G H z})\end{array}$} & \multicolumn{2}{|c|}{ ROHACELL } \\
\cline { 2 - 3 } & Simulated(dBW) & Discharge(dBW) \\
\hline 1.3 & 24.6 & $27.2^{\mathbf{1 , 2 , 3 , 4 , 5}}$ \\
\hline 1.6 & 28.3 & $27.4^{\mathbf{1 , 2 , 3 , 4}}$ \\
\hline 2.0 & 24.6 & $29.1^{\mathbf{1 , 2 , 3 , 4 , 5}}$ \\
\hline 2.5 & 28.3 & $31.2^{\mathbf{1 , 2 , 4}}$ \\
\hline 3.0 & 31.5 & - \\
\hline 3.5 & 34.1 & - \\
\hline 3.97 & 33.6 & - \\
\hline
\end{tabular}

\begin{tabular}{|c|c|c|}
\hline \multirow{2}{*}{$\begin{array}{c}\text { Frequency } \\
(\mathbf{G H z})\end{array}$} & \multicolumn{2}{|c|}{ TEFLON } \\
\cline { 2 - 3 } & Simulated(dBW) & Discharge(dBW) \\
\hline 1.3 & 20.0 & $18.9^{\mathbf{1 , 2}}$ \\
\hline 1.6 & 23.3 & $21.8^{\mathbf{1 , 2 , 3 , 4}}$ \\
\hline 2.0 & 26.3 & $23.7^{\mathbf{1 , 2}}$ \\
\hline 2.5 & 28.8 & $27.7^{\mathbf{1 , 2}}$ \\
\hline 3.0 & 28.5 & $30.3^{\mathbf{1 , 2 , 3 , 4}}$ \\
\hline 3.5 & 29.2 & $30.2^{\mathbf{1 , 3}}$ \\
\hline 3.97 & 29.3 & $29.8^{\mathbf{1 , 2 , 3 , 4}}$ \\
\hline
\end{tabular}

\begin{tabular}{|c|c|c|}
\hline \multirow{2}{*}{$\begin{array}{c}\text { Frequency } \\
\text { (GHz) }\end{array}$} & \multicolumn{2}{|c|}{ ULTEM 1000 } \\
\cline { 2 - 3 } & Simulated(dBW) & Discharge(dBW) \\
\hline 1.3 & 20.3 & $22.9^{1,2,3,4,5}$ \\
\hline 1.6 & 23.6 & $20.3^{1,2}$ \\
\hline 2.0 & 26.9 & $21.3^{\mathbf{1 , 2}}$ \\
\hline 2.5 & 29.5 & $25.3^{1,2,3}$ \\
\hline 3.0 & 28.7 & $27.8^{1,2,3,4,5}$ \\
\hline 3.5 & 29.6 & $27.9^{1,4}$ \\
\hline 3.97 & 29.6 & $28.8^{1,2,3,4}$ \\
\hline
\end{tabular}

Triggered Detection Systems:

${ }^{1}$ Nulling system

${ }^{2}$ Third harmonic

${ }^{3}$ Electrometer

${ }^{4}$ Photomultiplier

${ }^{5}$ Return losses

The discrepancies in the results are mainly associated to the uncertainty concerning the SEY properties used in the simulations, as compared to the actual SEY values of the dielectric samples. This difference appears to be higher for the Rohacell and Ultem 1000 samples than for all other samples. However, considering the current margins for multipactor analysis, specified in the European [20] and American [21] standards as $8 \mathrm{~dB}$ and $6 \mathrm{~dB}$, respectively, all the simulated results are well within the margins with no exceptions.

\section{IV.CONCLUSION}

In this paper, we have described the design of low-pass coaxial waveguide devices with a large operational bandwidth, specifically optimized to perform high power RF tests of dielectric samples. To this end, coaxial waveguide sections have been partially filled with dielectric materials commonly used in space applications (in particular, Alumina, Rexolite, Rogers 5870, Rohacell, Teflon and Ultem 1000 are considered). The test structures have been designed so that the maximum electric field occurs between the dielectric samples, thereby ensuring that multipactor will take place where the dielectric materials are located.

Simulated results for the RF multipactor threshold levels are shown for different values of the $f \times d$ product, and are compared with experimental data. Typical multipactor breakdown susceptibility charts have also been provided for all materials. They can effectively be used as a reference for future designs. Taking into account all degrees of uncertainty related to the multipactor breakdown characterization, reasonably good agreement between simulated and experimental results has been obtained in all cases. The results obtained demonstrate the validity of using an equivalent worst-case SEY curve (Aluminium) for multipactor breakdown prediction, at least with the dielectric materials 
under study. The data obtained are expected to be a solid engineering reference for the development of passive space components containing dielectric materials.

\section{ACKNOWLEDGMENT}

The authors would like to acknowledge the European High Power RF Space Laboratory (Valencia, Spain) for its contribution to this work - A laboratory funded by the European Regional Development Fund - A way of making Europe.

\section{REFERENCES}

[1] M Paillard et al., "Multilayer RF PCB for space applications: technological and interconnections trade-off," European Gallium Arsenide and Other Semiconductor Application Symp., Oct. 2005.

[2] M.T. Islam, M. Cho, M. Samsuzzaman and S. Kibria, "Compact antenna for small satellite applications [Antenna Applications Corner]," IEEE Antennas and Propagation Magazine, vol. 57, no. 2, pp. 30-36, April 2015 .

[3] W.M. Abdel Wahab, D. Busuioc and S. Safavi-Naeini, "Low cost planar waveguide technology-based dielectric resonator antenna (DRA) for millimeter-wave applications: Analysis, design, and fabrication," IEEE Trans. Antennas and Propagation, vol. 58, no. 8, pp. 2499-2507, Aug. 2010.

[4] S.J. Fiedziuszko et al., "Dielectric materials, devices, and circuits," IEEE Trans. Microw. Theory Techn., vol. 50, no. 3, pp. 706-720, Mar 2002.

[5] S. Michizono, Y. Saito, S. Fukuda, K. Hayashi, S. Anami, "RF windows used at S-band pulsed klystrons in the KEK linac," $13^{\text {th }}$ Proc. Int Vacuum Congr. and the 9th Int. Conf. on Solid Surfaces, vol. 47, no, 6-8, pp. 625-628, Jun. 1996.

[6] S.J. Penn, N.M. Alford and T.W. Button, "High Q dielectric resonators using $\mathrm{YBa}_{2} \mathrm{Cu}_{3} \mathrm{O}_{\mathrm{x}}$ thick films and polycrystalline dielectrics," IEEE Trans. Applied Superconductivity, vol. 7, no. 2, pp. 3500-3503, Jun. 1997.

[7] A. Manchec et al., "Study of a C-band cross-coupled dual-behavior resonator filter with spurious responses suppression for a space application," European Microw. Conf., Munich, 2007, pp. 882-885, Dec. 2007.

[8] P. Hogue, M Rooney, A. Webb, D.J. Price, "Rohacell ${ }^{\circledR}$ foam for space applications," Proc. Int. SAMPE Symp. and Exhibition, Jan. 2007.

[9] S. Saraf et al., "Ground testing and flight demonstration of charge management of insulated test masses using UVLED electron photoemission," Classical and Quantum gravity, No. 33, Jul. 2016.

[10] K. Shamsaifar, T. Rodriguez and J. Haas, "High-Power Combline Diplexer for Space," IEEE Trans. Microw. Theory Techn., vol. 61, no. 5 , pp. 1850-1860, May 2013.

[11] E. Doumanis, G. Goussetis, W. Steffe, D. Maiarelli and S.A. Kosmopoulos, "Helical resonator filters with improved power handling capabilities for space applications," IEEE Microwave and Wireless Components Letters, vol. 20, no. 11, pp. 598-600, Nov. 2010.

[12] European Cooperation for Space Standarization (ECSS), "Space product assurance: Procurement of printed circuit boards," ECSS-Q-ST-70-11C, 15 November 2008, ESA-ESTEC Requirements \& Standards Division, Noordwijk, The Netherlands

[13] J.R.M. Vaughan, "Multipactor," IEEE Trans. Electron Devices, vol. 35, no. 7, pp. 1172-1180, Jul 1988.

[14] R.A. Kishek, Y.Y. Lau, L. K. Ang, A. Valfells, and R.M. Gilgenbach, "Multipactor discharge on metals and dielectrics: Historical review and recent theories," Phys. Plasmas, vol.5, no.5, pp. 2120-2126, May. 1998.

[15] A.M. Perez et al., "Prediction of multipactor breakdown thresholds in coaxial transmission lines for traveling, standing, and mixed waves," IEEE Trans. Plasma Science, vol. 37, no. 10, pp. 2031-2040, Oct. 2009.

[16] D. González-Iglesias, Ó. Monerris, B.G. Martínez, M.E. Díaz, V.E. Boria and P.M. Iglesias, "Multipactor RF breakdown in coaxial transmission lines with digitally modulated signals," IEEE Trans. Electron Devices, vol. 63, no. 10, pp. 4096-4103, Oct. 2016.

[17] A.J. Hatch, H.B. Williams, "Multipacting modes of high-frequency gaseous breakdown,” Phys. Rev.,112, 3, 681 (1958).

[18] A. Woode and J. Petit, "Diagnostic investigations into the multipactor effect, susceptibility zone measurements and parameters affecting a discharge," ESA, Noordwijk, The Netherlands, ESA Working Paper 1556, Nov. 1989.

[19] S. Anza, M. Mattes, C. Vicente, J. Gil, D. Raboso, V.E. Boria, and B. Gimeno, "Multipactor theory for multicarrier signals," Phys. Plasmas, vol.18, no.3, Mar. 2011.

[20] European Cooperation for Space Standarization (ECSS), "Multipacting Design and Test", volume ECSS-20-01A, edited by ESA-ESTEC. ESA Publication Division, The Netherlands, May 2003

[21] T.P. Graves, "Standard/Handbook for Radio Frequency (RF) Breakdown Prevention in Spacecraft Components," AEROSPACE REPORT NO. TOR-2014-02198.

[22] G. Torregrosa, A. Coves, C.P. Vicente, A.M. Perez, B. Gimeno and V.E. Boria, "Time evolution of an electron discharge in a parallel-plate dielectric-loaded waveguide," IEEE Electron Device Letters, vol. 27, no. 7, pp. 619-621, July 2006.

[23] G. Torregrosa-Penalva, Á. Coves, B. Gimeno Martinez, I. Montero, C. Vicente and V.E. Boria, "Multipactor susceptibility charts of a parallelplate dielectric-loaded waveguide," IEEE Trans. Electron Devices, vol. 57, no. 5, pp. 1160-1166, May 2010.

[24] Á. Coves, G. Torregrosa-Penalva, C. Vicente, B. Gimeno and V.E. Boria, "Multipactor discharges in parallel-plate dielectric-loaded waveguides including space-charge effects," IEEE Trans. Electron Devices, vol. 55, no. 9, pp. 2505-2511, Sep. 2008.

[25] A. Berenguer, A. Coves, F. Mesa, E. Bronchalo, B. Gimeno and V.E. Boria, "Calculation of the electrostatic field in a dielectric-loaded waveguide due to an arbitrary charge distribution on the dielectric layer," 2016 Progress in Electromagnetic Research Symp. (PIERS), Shanghai, pp. 3251-3255, Nov. 2016.

[26] J. Vague, M. Guglielmi, V.E. Boria, S. Anza, C. Vicente, "Coaxial waveguide filters for multipactor characterization of dielectrics used in space applicationsk" IEEE MTT-S Int. Microwave Workshop Series on Advances Materials and Processes, Sep. 2017.

[27] S. Anza, C. Vicente, D. Raboso, J. Gil, B. Gimeno and V.E. Boria, "Enhanced prediction of multipaction breakdown in passive waveguide components including space charge effects," IEEE MTT-S Int. Microw. Symp. Dig., Atlanta, GA, USA, pp. 1095-1098, Sep. 2008.

[28] G. Gerini and M. Guglielmi, "Efficient integral equation formulations for admittance or impedance representation of planar waveguide junctions," IEEE MTT-S Int. Microw. Symp. Dig., Baltimore, MD, USA, pp. 1747-1750 vol.3, Ago. 1998.

[29] .V. Mclevige, T. Itoh, R. Mittra, "New waveguide structures for millimiter-wave and optical integrated circuits," IEEE Trans. Microw. Theory Techn., vol. 23, no. 10, pp. 788-794, Oct. 1975.

[30] R. Levy and T.E. Rozzi, "Precise design of coaxial low-pass filters," IEEE Trans. Microw. Theory Techn., vol. 16, no. 3, pp. 142-147, Mar 1968.

[31] D.M.Pozar, Microwave Engineering, John Wiley and Sons, 2012. $4^{\text {th }}$ Edition.

[32] E. Tarín, P. Soto and V.E. Boria, "Accurate modal representation of arbitrarily shaped multiconductor transmission lines enclosed in homogeneous waveguides," IEEE MTT-S Int. Microw. Symp. Dig., Long Beach, CA, USA, pp. 1067-1070, Jun. 2005.

[33] J.R.M. Vaughan, "A new formula for secondary emission yield," IEEE Trans. Electron Devices, vol. 36, no. 9, pp. 1963-1967, Sep. 1989.

[34] C. Vicente et. al., "Multipactor Breakdown Prediction in Rectangular Waveguide Based Components," IEEE MTT-S Int. Microw. Symp. Dig., Long Beach, CA, USA, pp. 1055-1058, Jun. 2005.

[35] R. Mata, L. Mercadé, D. Bañón, J.M. Socuellamos, B. Gimeno, V.E. Boria, D. Raboso, "Study of the charge processes involved in the secondary electron emission yield measurements of dielectric materials", Proc. 9th Int. Workshop on Multipactor, Corona and Passive Intermodulation, ESTEC, Noordwijk, The Netherlands, April 5-7 2017. 


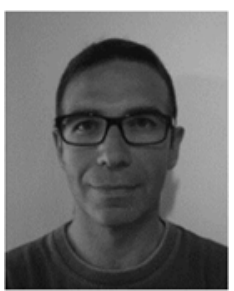

J. Vague was born in Valencia, Spain, in 1970. He received the Electronic Engineering degree from the Universidad de Valencia, Burjassot, Spain, in 2003. $\mathrm{He}$ is currently pursuing his $\mathrm{Ph}$. D. degree in Electronic Engineering. His main research interests are the design of microwave passive devices, in particular filters and non-reciprocal devices as well as the improvement in manufacturing processes in the RF and microwave range. He is currently a Technical Researcher in charge of several laboratories with the Department of Communications, UPV.

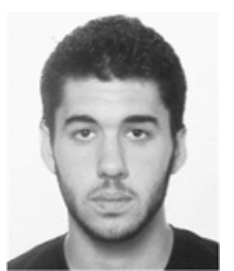

J.C. Melgarejo was born in Alicante, Spain in 1993. He obtained his bachelor's degree in Telecommunications from the Universitat Politècnica de València (UPV) in 2015. From there, he continued his studies with the UPV where he pursued a double Master's in Telecommunications Systems. In 2017, he began his Ph.D. at the university where his main research interests have been investigating microwave passive devices and new manufacturing techniques for satellite components.

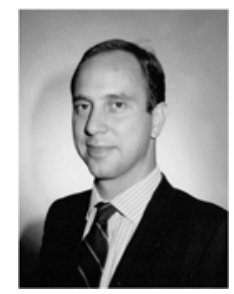

M. Guglielmi (F'13) was born in Rome, Italy, in 1954. He received the Laurea degree in ingegneria elettronica from the University of Rome "La Sapienza," Rome, in 1979 , the M.S. degree in electrical engineering from the University of Bridgeport, Bridgeport, CT, USA, in 1982, and the Ph.D. degree in electrophysics from the Polytechnic University, Brooklyn, NY, USA, in 1986 In 1980, he attended the Scuola di Specializzazione in Elettromagnetismo Applicato, University of Rome "La Sapienza." From 1984 to 1986, he was an Academic Associate with the Polytechnic University, where he was also Assistant Professor from 1986 to 1988. From 1988 to 1989, he was an Assistant Professor with the New Jersey Institute of Technology, Newark, NJ, USA. In 1989, he joined the RF System Division, European Space Agency, European Space Research and Technology Centre (ESTEC), Noordwijk, The Netherlands, as a Senior Microwave Engineer, where he was in charge of the development of microwave filters and electromagnetic simulation tools. In 2001, he became the Head of the Technology Strategy Section, ESTEC, where he contributed to the development of management processes and tools for the formulation of a European strategy for space technology research and development. Dr. Guglielmi retired from ESA in 2014, and is currently an invited senior researcher with the Polytechnic University of Valencia, Valencia, Spain. Dr. Guglielmi was the recipient of a Fulbright Scholarship in Rome, Italy, in 1981, and the Halsey International Scholarship Programme of the University of Bridgeport, Bridgeport, CT, USA. Dr. Guglielmi has been elevated to the grade of Fellow of the IEEE in January 2013 "For contributions to multimode equivalent networks and microwave filter design".

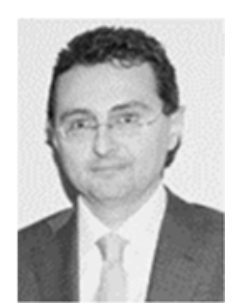

Vicente E. Boria (S'91-A'99-SM'02-F'18) was born in Valencia, Spain, on May 18, 1970. He received his "Ingeniero de Telecomunicación" degree (with firstclass honors) and the "Doctor Ingeniero de Telecomunicación" degree from the Universidad Politécnica de Valencia, Valencia, Spain, in 1993 and 1997, respectively. In 1993 he joined the "Departamento de Comunicaciones", Universidad Politécnica de Valencia, where he has been Full Professor since 2003. In 1995 and 1996, he was holding a Spanish Trainee position with the European Space Research and Technology Centre, European Space Agency (ESTEC-ESA), Noordwijk, The Netherlands, where he was involved in the area of EM analysis and design of passive waveguide devices. He has authored or coauthored 10 chapters in technical textbooks, 180 papers in refereed international technical journals, and over 200 papers in international conference proceedings. His current research interests are focused on the analysis and automated design of passive components, left-handed and periodic structures, as well as on the simulation and measurement of power effects in passive waveguide systems.

Dr. Boria has been a member of the IEEE Microwave Theory and Techniques Society (IEEE MTT-S) and the IEEE Antennas and Propagation Society (IEEE AP-S) since 1992. He acts as a regular reviewer of the most relevant IEEE and IET technical journals on his areas of interest. Presently, he serves as Associate Editor of IEEE Microwave and Wireless Components Letters and IET Electronics Letters, and as Editorial Board member of International Journal of RF and Microwave Computer-Aided Engineering. He is also member of the Technical Committees of the IEEE-MTT International Microwave Symposium and of the European Microwave Conference.

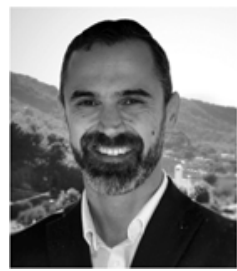

S. Anza received the B.S. degree in telecommunications engineering and the $\mathrm{Ph} . \mathrm{D}$. degree from the Universidad Politecnica de Valencia,Valencia, Spain. He is currently with Aurora Software and Testing S.L.U. (now CST/3DS), Valencia. His current research interests include the areas of theory and numerical techniques for the modelling and prediction of nonlinear phenomena in RF high power devices for space applications.

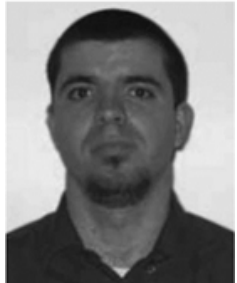

C. Vicente (M'08) was born in Elche, Spain, in 1976. $\mathrm{He}$ received the Dipl. degree in physics from the Universidad de Valencia, Valencia, Spain, in 1999, and the Dr.-Ing degree in engineering from the Technical University of Darmstadt, Darmstadt, Germany, in 2005. From 1999 to the beginning of 2001, he was a Research Assistant with the Department of Theoretical Physics, Universidad de Valencia. From 2001 to 2005, he was a Professor Assistant with the Institute of Microwave Engineering, Technical University of Darmstadt. Since 2005, he has been with the Microwave Applications Group, Universidad Politecnica de Valencia, Valencia, Spain. In 2006, he co-founded Aurora Software and Testing S. L. U. (now CST/3DS), which is devoted to the software development for the telecommunications sector. His research concerns the analysis and design of passive components for communications satellites with a special emphasis on high-power practical aspects such as passive intermodulation, corona discharge, and multipaction.

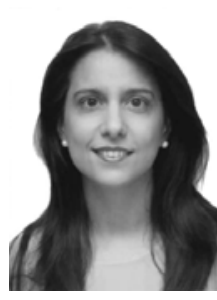

$\mathbf{M}^{\mathbf{a}}$ Rocio Moreno was born in Valencia, Spain, in 1982. She received the Telecommunications Engineering degree from the Universitat Politècnica de València (UPV), Valencia, Spain, in 2009. From 2008 to 2011 she worked as a researcher with the UPV in the field of the Remote Sensing. In 2012 she started to work in the High Power RF Laboratory of Val Space Consortium as Testing Engineer. Her main testing interest areas are passive intermodulation products, Multipactor, Corona and power handling.

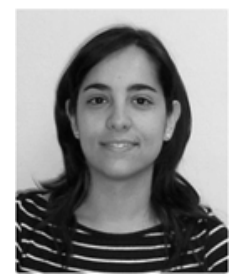

Máriam Taroncher was born in Lliria, Valencia, Spain, in October 8th, 1979. She received the Telecommunications Engineering degree from the Universidad Politécnica de Valencia (UPV), Valencia, Spain, in 2003. From 2002 to 2004, she was a Fellow Researcher with the UPV in the field of analysis methods for waveguide structures. Since 2004, she has been a Technical Researcher in charge of the experimental laboratory for high power effects in waveguide devices at the Research Institute iTEAM, UPV. In 2006 she was awarded a Trainee position at the European Space Research and Technology Centre, European Space Agency (ESTEC-ESA), Noordwijk, The Netherlands, where she worked in the Payload Systems Division Laboratory in the area of Multipactor, Corona Discharge and Passive Intermodulation (PIM) effects. Since 2009, she is Engineer Technician at ESA-VSC High Power RF Laboratory. 


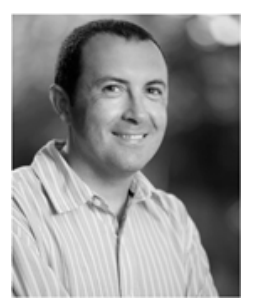

Benito Gimeno Martínez (M’01) was born in Valencia, Spain, on January 29, 1964. He received the Licenciado degree in physics and the Ph.D. degree from the Universidad de Valencia, Burjassot, Spain, in 1987 and 1992, respectively. He was a Fellow with the Universidad de Valencia from 1987 to 1990. Since 1990, he has been an Assistant Professor with the Departamento de Física Aplicada y Electromagnetismo and the Instituto de Ciencia de Materiales (ICMUV), Universidad de Valencia, where he became an Associate Professor in 1997. During 1994-1995, he was with the European Space Research and Technology Centre, European Space Agency, as a Research Fellow. In 2003, he obtained a fellowship from the Spanish Government for a short stay (three months) at the Universita degli Studi di Pavia, Pavia, Italy, as a Visiting Scientific. His current research interests include computer-aided techniques for analysis of microwave and millimeter-wave passive components for space applications, waveguides, and cavity structures, including dielectric objects, electromagnetic bandgap structures, frequency-selective surfaces, and nonlinear phenomena appearing in power microwave subsystems (multipactor effect, corona effects, and passive intermodulation phenomena).

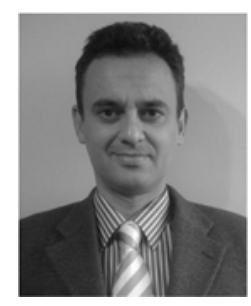

David Raboso received the Degree in physics from the Autonomous University of Madrid, Madrid, Spain and the master's degree in space engineering from the University of Delft, Delft, The Netherlands. In 1992, he joined the European Space Agency, The Netherlands, where he became responsible for all activities related to RF breakdown in space microwave components. He has co-authored over 100 articles in prestigious journals and a co-inventor of nine patents. 